\title{
Vereinfachte photometrische Calciumbestimmung im Serum ohne Eiweißfällung
}

\author{
Von J. Hoeflmayr und R. Fried \\ Aus den wissenschaftlichen Laboratorien der Firma Dr. Heinz Haury, Müncben
}

(Eingegangen am 8. Januar/26. Februar 1973)

Eine vereinfachte Methode zur Bestimmung des Calciums im Serum ohne Eiweißfällung wird angegeben. Der Calciumwert wird aus der Extinktionsdifferenz des Farbkomplexes mit Glyoxal-bis(2-hydroxyanil) vor und nach Zugabe von Äthylendiamintetraessigsäure bestimmt. Die Präzision und Richtigkeit der Methode sind ausgezeichnet.

\section{Simplified photometric determination of Calcium in serum without deproteinisation}

A simplified method for the determination of Calcium in serum without protein precipitation is described. The calcium values are obtained from the difference in optical density of the Glyoxal-bis(2-hydroxyanil) colour complex before and after the addition of EDTA. Precision and accuracy of the method are excellent.

Auf der Suche nach einem Reagenz für eine einfache photometrische Calciumbestimmung im Serum, das so empfindlich ist, daß diese Bestimmung im stark verdünnten Serum und folglich ohne Eiweißfällung durchzuführen ist, sind wir auf das Glyoxal-bis(2hydroxyanil) gestoßen. Ursprünglich von KERR (1) für die photometrische Calciumbestimmung im Regenwasser vorgeschlagen, wurde dieses Reagenz zur photometrischen Serumcalciumbestimmung von MAGER und FARESE (2) erstmalig verwendet. BURR (3) hat dieses Reagenz für eine automatische Calciumbestimmung im Serum eingesetzt.

Wir haben die von MAGER und FARESE vorgeschlagene Methode überprüft und zur weiteren Vereinfachung modifiziert und konnten dabei die vorzügliche Eignung von Glyoxal-bis(2-hydroxyanil) für diese Bestimmung ohne Eiweißfällung unter Beweis stellen. Die Methode beruht auf folgendem Prinzip: Das Serum wird durch einen alkalischen Boratpuffer stark verdünnt und mit einer methanolischen Glyoxal-bis(2-hydroxyanil)-Lösung versetzt. Dabei bildet sich ein orange-roter Farbkomplex, dessen Intensität bei $510-560 \mathrm{~nm}$ (z. B. $\mathrm{Hg}$ 546) gemessen wird. Durch Zusatz von Äthylendiamintetraessigsäure wird dieser Komplex zerstört und danach die Messung wiederholt. Die Differenz der beiden Messungen ergibt nur den auf der Calciummenge beruhenden Extinktionswert; eventuelle Trübungen werden dadurch eliminiert.

\section{Material und Methoden}

Reagenzien ${ }^{1}$ )

1. Pufferlösung pH 13

$875 \mathrm{mmol} / 1$ di-Natriumtetraborat und $83 \mathrm{mmol} / 1$ Natriumhydroxyd

2. Glyoxal-bis(2-hydroxyanil)-Lösung

$0,31 \mathrm{mmol} / 1$ Glyoxal-bis(2-hydroxyanil) in Methanol

3. Åthylendiamintetraessigsäure-Lösung $134 \mathrm{mmol} / 1$

4. Standard-Lösung

$2,5 \mathrm{mmol} / \mathrm{l}(10 \mathrm{mg} / 100 \mathrm{ml})$ Calcium.

\section{Arbeitsvorschrift}

In drei calciumfreie Reagenzgläser (z. B. Plastikröhrchen) für Analyse, Standard und Leerwert werden je $3 \mathrm{ml}$ Pufferlösung pipettiert. Zur Analyse werden $0,05 \mathrm{ml}$ Serum, zum Standard $0,05 \mathrm{ml}$ Standard-Lösung gegeben. Dann wird allen Proben 1,0 ml Glyoxal-bis(2-hydroxyanil)-Lösung zugefügt und gut gemischt. Die Proben werden in sauberen Küvetten genau $10 \mathrm{~min}$ nach Zugabe der letzten Lösung gegen destilliertes Wasser bei 510 bis $560 \mathrm{~nm}$ (z. B. Hg 546, Spektralphotometer $520 \mathrm{~nm}$ ) gemessen: $=$ Extinktion I. Dann gibt man in jede Küvette $0,05 \mathrm{ml}$ Äthylendiamintetraessigsäure-Lösung, mischt und mißt nach $10 \mathrm{~min}$ erneut gegen destilliertes Wasser: = Extinktion II.

Die Berechnung erfolgt nach der Formel:

$$
\frac{(\text { Analyse Ext. I-II) }-(\text { Leerwert Ext. I-II) }}{\text { (Standard Ext. I-II) - (Leerwert Ext. I-II) }} \times 2,5=\mathrm{mmol} / 1(\times 10=\mathrm{mg} / 100 \mathrm{ml}) \text { Calcium im Serum. }
$$

\section{Ergebnisse und Diskussion}

Wie MAger et al. sowie Burr konnten auch wir uns durch Zusatzversuche überzeugen, daß Magnesiumund Phosphat-Ionen in einer im Serum üblichen Konzentration nicht stören. Der von MAGER et al. vorgeschlagene Zusatz eines mit Wasser mischbaren organischen Lösungsmittels ist nach unseren Untersuchungen unnötig. Dagegen hat der Zusatz von
Äthylendiamintetraessigsäure zur Zerstörung des Komplexes vor der zweiten Messung die Methode auch für schwach lipämische Seren brauchbar gemacht.

$\mathrm{Da}$ die entstehende Farbe nicht konstant ist, muß die Zeit zwischen Zugabe der Glyoxal-bis(2-hydroxyanil)Lösung und der Messung für alle Proben gleich sein.

1) Enthalten in HAURYTEST „Calcium-S“ Firma Dr. Heinz Haury, 8 München 40, Postfach 400806. 
Tab. 1

Vergleich der flammenphotometrischen Calciumbestimmung mit der beschriebenen Methode

\begin{tabular}{|c|c|c|c|}
\hline \multirow[b]{2}{*}{ Serum Nr. } & \multicolumn{2}{|c|}{$\mathrm{mg} / 100 \mathrm{ml}$ Calcium im Serum } & \multirow{2}{*}{$\Delta \%$} \\
\hline & $\begin{array}{l}\text { Flammen- } \\
\text { photometer }\end{array}$ & $\begin{array}{c}\text { Glyoxal-bis } \\
\text { (2-hydroxyanil) }\end{array}$ & \\
\hline 1 & 8,7 & 8,65 & $-0,58$ \\
\hline 2 & 9,6 & 9,42 & $-1,87$ \\
\hline 3 & 9,5 & 9,86 & $+3,79$ \\
\hline 4 & 9,3 & 9,58 & $+3,0$ \\
\hline 5 & 10,4 & 10,5 & $+0,96$ \\
\hline 6 & 8,6 & 9,0 & $+4,65$ \\
\hline 7 & 8,6 & 8,7 & $+1,16$ \\
\hline 8 & 10,0 & 10,8 & $+8,00$ \\
\hline 9 & 9,2 & 9,55 & $+3,80$ \\
\hline 10 & 9,4 & 9,65 & $+2,65$ \\
\hline 11 & 9,2 & 9,58 & $+4,13$ \\
\hline 12 & 9,4 & 9,3 & $-1,06$ \\
\hline 13 & 9,6 & 9,8 & $+2,08$ \\
\hline 14 & 9,6 & 9,8 & $+2,08$ \\
\hline 15 & 9,0 & 9,4 & $+4,44$ \\
\hline 16 & 9,2 & 9,4 & $+2,17$ \\
\hline 17 & 9,0 & 9,5 & $+5,55$ \\
\hline 18 & 9,4 & 9,46 & $+0,63$ \\
\hline 19 & 8,8 & 8,65 & $-1,70$ \\
\hline \multirow[t]{2}{*}{20} & 9,0 & 8,7 & $-3,33$ \\
\hline & 9,28 & 9,47 & \\
\hline
\end{tabular}

Korrelationskoeffizient: $\mathbf{r}=0,885$

Regressionsgerade: $y=0,85+0,930 x$

Man gibt diese Lösung in dem Arbeitsrhythmus zu, in dem nach 10 min die Ablesung der Proben exfolgen kann.

Die Eichkurve ist bis über $5 \mathrm{mmol} / 1(20 \mathrm{mg} / 100 \mathrm{ml})$ Calcium im Serum geradlinig.

Durch Verwendung von Plastik-Einwegröhrchen vermeidet man die Reinigung der Zentrifugengläser mit verdünnter Salzsäure, um sie absolut frei von Calcium zu bekommen.

Um bei der Zugabe von Äthylendiamintetraessigsäure für alle Proben die gleichen Verdünnungen zu erhalten, werden die Ansätze zur Messung entweder vollständig in die Küvetten geleert, oder wenn dies nicht möglich ist, die Küvetten bis zur gleichen Höhe gefüllt.

Die Reproduzierbarkeit der Methode ist ausgezeichnet. In der Serie konnte bei 20 Bestimmungen eines Serums nach der Normalmethode unter Verwendung von
Tab. 2

Vergleich der Calciumbestimmungsmethode nach WEBSTER mit der beschriebenen Methode

\begin{tabular}{|c|c|c|c|}
\hline \multirow{2}{*}{$\frac{\text { Serum Nr. }}{21}$} & \multicolumn{2}{|c|}{$\begin{array}{cc}\text { mg/100 ml Calcium im Serum } \\
\text { Mod. Methode } & \text { Glyoxal-bis } \\
\text { nach WEBSTER } & \text { (2-hydroxyanil) }\end{array}$} & \multirow{2}{*}{$\begin{array}{r}\Delta \% \\
+2,10\end{array}$} \\
\hline & 9,5 & 9,7 & \\
\hline 22 & 9,6 & 9,9 & $+3,12$ \\
\hline 23 & 9,3 & $9,7 \cdot 1$ & $+4,30$ \\
\hline 24 & 8,9 & 9,7 & $\begin{array}{r}+8,98 \\
\end{array}$ \\
\hline 25 & 13,4 & 12,8 & $-4,47$ \\
\hline 26 & 5,8 & 5,7 & $-1,72$ \\
\hline 27 & 11,4 & 12,1 & $+6,14$ \\
\hline 28 & 8,7 & 9,0 & $+3,44$ \\
\hline 29 & 9,7 & 9,1 & $-6,18$ \\
\hline 30 & 5,8 & 6,5 & $-12,06$ \\
\hline 31 & 10,1 & 10,1 & $+0,00$ \\
\hline 32 & 8,9 & 9,0 & $+1,12$ \\
\hline 33 & 8,0 & 8,4 & $+5,00$ \\
\hline 34 & 9,7 & 9,7 & $+0,00$ \\
\hline 35 & 8,8 & 9,3 & $+5,68$ \\
\hline 36 & 9,5 & 8,7 & $-8,42$ \\
\hline 37 & 10,2 & 10,3 & $+0,98$ \\
\hline 38 & 11,0 & 10,6 & $-3,63$ \\
\hline 39 & 10,1 & 9,6 & $-4,95$ \\
\hline \multirow[t]{2}{*}{40} & 9,3 & 9,7 & $+4,30$ \\
\hline & 9,39 & 9,48 & \\
\hline
\end{tabular}

Korrelationskoeffizient: $r=0,961$

Regressionsgerade: $y=0,03+1,007 x$

Marburg-Pipetten eine relative Standardabweichung von $\pm 0,01 \%$ ermittelt werden. Die Reproduzierbarkeit der Ergebnisse bei Untersuchung von Tag zu Tag ergab diesen Wert mit $\mathrm{V}= \pm 1,05 \%$. Die hohe Empfindlichkeit des Reagenz gestattet noch $0,0125 \mathrm{mmol} / 1$ Calcium im Serum sicher zu erfassen. Die Richtigkeit der Bestimmung wurde durch Vergleich mit der flammenphotometrischen Bestimmung und der von uns modifizierten Chloranilat-Methode (4) nach WEBSTER (5) überprüft. Im Vergleich mit dem Flammenphotometer ergab sich ein Korrelationskoeffizient von $\mathrm{r}=0,885$ und eine Regressionsgerade von $\mathrm{y}=0,85+$ $0,930 \mathrm{x}$. Bei der Chloranilatmethode waren die entsprechenden Werte $\mathrm{r}=0,961$ und $\mathrm{y}=0,03+1,007 \mathrm{x}$.

Wir danken Frl. L. RExirrke für die exakte Durchführung der Untersuchungen.

\section{Literatur}

1. Kerr, J. R. W. (1960), Analyst 85, 867 zit. nach l. c. (2). - Mayr, J., Fried. R. \& Stadelmann, W. (1964), Árztl. Lab. 10, 2. Mager, M. \& Farese, G. (1966), Clin. Chem. 12, 234-242. 3. Burr, R. G. (1969), Clin. Chem. 14, 1191-1197. - 4. HoefL127-129. - 5. Webster, W. W. (1962), Am. J. Clin. Pathol. 37, $330-333$

Dr. med. J. Hoeflmayr Dr. ter. nat. R. Fried 8 München 40

Schleißheimer Str. 343 